\title{
Rheological characterization of polystyrene melts dissolved with supercritical nitrogen fluid during microcellular injection moulding
}

\author{
Shia-Chung Chen, ${ }^{12}$ Ming-Hsiu Chung, ${ }^{12}$ Yu-Wan Lin, ${ }^{12}$ Ping-Shun Hsu, ${ }^{12}$ Shyh- \\ Shin Hwang, ${ }^{3}$ Pe-ming Hsu ${ }^{4}$
}

1 R\&D Centre for Membrane Technology, Chung Yuan University, Chung-Li 320, Taiwan, R.O.C.; fax: + 886-3-265-4388; email: shiachun@cycu.edu.tw

2 Department of Mechanical Engineering, Chung Yuan University, Chung-Li 320, Taiwan, R.O.C.; fax: + 886-3-265-4388; email: shiachun@cycu.edu.tw

3 Department of Mechanical Engineering, Ching Yun University, Chung-Li 320, Taiwan, R.O.C.; fax: + 886-3-4683301; email: stanhwang@cyu.edu.tw

${ }^{4}$ Department of Computer Application Engineering, Far East University, Tainan 774, Taiwan, R.O.C.; fax: +886-6-5977912; email: pphsu@cc.fec.edu.tw

(Received: 31 July, 2009; published: 16 November, 2010)

\begin{abstract}
There are several benefits of using the supercritical fluid microcellular injection moulding process. The part weight, melt temperature, viscosity, moulding pressure, shrink/warpage, and cooling/cycle time are all significantly reduced. The purpose of this study is to investigate the rheological behaviour of PS melt dissolved SCF of nitrogen during Microcellular Injection Moulding process applied with Gas Counter Pressure (GCP) technology. The application of gas into the mould cavity prior to the melt filling provides a counter force against the melt front advancement, restricting the foaming process during the melt filling stage. A slit cavity is designed to measure the pressure drop of polystyrene mixed with $0.4 \mathrm{wt} \%$ supercritical nitrogen fluid under different mould temperatures $\left(185^{\circ} \mathrm{C}, 195^{\circ} \mathrm{C}\right.$, and $\left.205^{\circ} \mathrm{C}\right)$, injection speeds $(5,10$, and $15 \mathrm{~mm} / \mathrm{s})$ as well as counter pressures $(0$, 150,300 bars). It was found that melt viscosity is reduced by up to $30 \%$ when GCP is increased from 50 to 150 bar as compared to conventional injection moulding. The non-nucleation mixture melt obtained by using a GCP of 300 bar has $32 \sim 49 \%$ lower viscosity. In addition, the glass transition temperature, $T_{g}$, was found to be reduced from $96{ }^{\circ} \mathrm{C}$ to $50{ }^{\circ} \mathrm{C}$ when the applied GCP is 300 bar.
\end{abstract}

\section{Introduction}

Thermoplastic foaming was introduced in the extrusion process in 1950. Then, it was applied in the injection moulding process. Foaming materials have several advantages like high impact strength, heat and sound insulation, and less material being required. However, it has disadvantages such as low tensile strength and inhomogeneous density. The foaming agent can induce physical or chemical foaming. The former uses a physical phase change to become a foaming material while the latter uses a chemical reaction that releases gas to become a foaming material. Due to environmental problems, physical foaming is more popular and among that microcellular foaming is the most promising process. The difference between normal and microcellular foaming is the size of the foam. The size of microcellular foaming is less than $100 \mu \mathrm{m}$. The microcellular process was first introduced by N. P. Suh [1, 2] in 1980. Then, Trexel Co. Ltd commercialized it as the MuCell process. This process is made by introducing the controlled gas during the 
injection stage cycle to create millions of micron-sized voids in solid thermoplastic polymer parts. This process requires four steps [3]: 1.gas dissolution, 2.nucleation, 3.cell growth, and 4.shaping. It has several advantages; weight of the parts, process conditions (melt temperature, viscosity, and clamp force), shrink/warpage, dimensional instability, and cooling/cycle time are all reduced.

In recent years, viscosity reduction of polymers using MuCell process has been of great interest in the realm of polymer processing, and investigators have presented rheological behaviour for microcellular injection moulding [4-6]. The viscosity of polymer dissolved with supper critical fluid (SCF) cannot be measured by standard methods. Mendelson [7] designed a pressurized chamber at the exit of a plungertype capillary viscometer for preventing bubble formation. Gerhardt et al. [8] and Kwag et al. [9] measured the viscosity reduction of polymer/ $/ \mathrm{CO}_{2}$ solutions using a sealed high pressure capillary rheometry with back pressure assemblies.

In order to describe the polymer/SCF flow behaviour, Lan and Tseng [10] studied the rheological behaviour of a $\mathrm{PP} / \mathrm{ScCO}_{2}$ (supper critical $\mathrm{CO}_{2}$ fluid) mixture using a slit die on an injection moulding machine. The shear rate in their work covered a larger range, in the order of $10,000 \mathrm{~s}^{-1}$. Lee et al. [11] proposed a generalized viscosity model containing eight adjustable parameters in which the free volume was described as a function of temperature, pressure, and gas concentration. Gerhardt et al. [8] and Kwag et al. [9] used a viscoelastic scaling technique to shift experimental data to create a master curve. Royer et al. $[12,13]$ employed two types of viscoelastic scaling models combined with predictions for $T_{g}$ depression

One of the biggest challenges that MuCell encountered by physical blowing agent is the surface quality. The surface of MuCell components frequently appear with silverlike striking. Because, it is drifting the fluid flowing out at the melt front and the polymer bubbles were destroyed by shear at the surface of the mould. It was reported that the surface quality can be improved by the gas counter pressure (GCP) process [14]. By using GCP in the mould the early foaming up of the gas loaded polymer melt may be prevented. The pressure inside the mould keeps the gas in solution on the flow front. That prevents the creation of surface swirls caused by dissolved gas between melt and mould. Initially, gas counter pressure technology was used in industry in the 1980s. Recently, an injection moulding process called AMOTEC (Asahi Moulding Technology of $\mathrm{CO}_{2}$ ) [15] was invented to control surface roughness and prevents surface defects in solidified plastic products by exploiting the plasticization effects of dissolved $\mathrm{CO}_{2}$. GCP is thus not a new process.

In this study, a gas counter pressure system was established (Fig.1). Depending on the counter pressure value, it can maintain the melt dissolved with SCF in a single phase state or partial foaming during melt filling stage of MuCell process when the gas counter pressure reaches the flow front. The sequence of the MuCell injection moulding process using Gas Counter Pressure (GCP) is as follows:

a) Mould closing, and setting the gas pressure.

b) Injection of stable, high pressure gas.

c) Injection $\mathrm{PS} / \mathrm{ScN}_{2}$ (supper critical $\mathrm{N}_{2}$ fluid) melt into the cavity, and use of the gas relief valve to control the cavity pressure until the end of the injection process.

d) Cooling and opening the mould. 


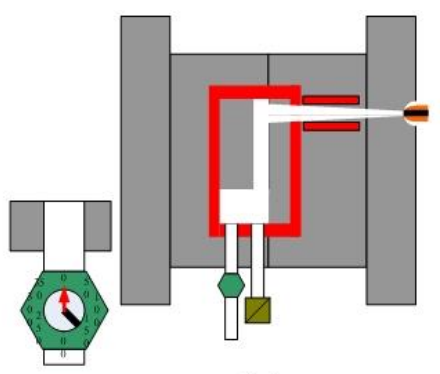

(a)

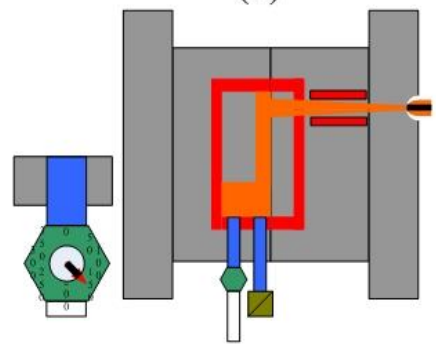

(c)

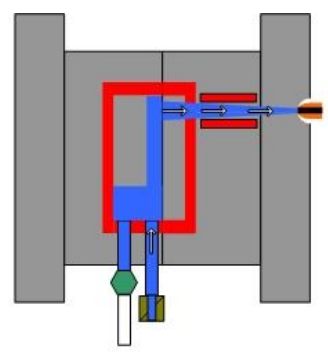

(b)
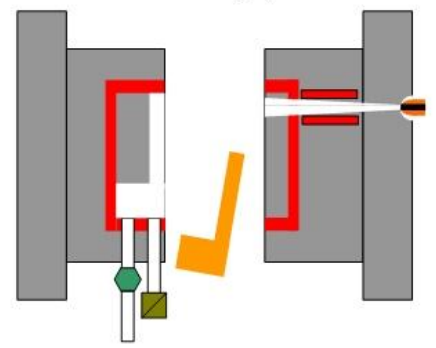

(d)

Fig. 1. Process for MuCell with Gas Counter Pressure (a) Mould close and setting of gas pressure; (b) Gas injection into cavity; (c) Melt injection and the cavity pressure controlled by the gas controller valve; (d) Product injection. [16]

We also established a rheology measuring system for MuCell injection moulding with gas counter pressure under different injection shear rates. This system consists of four main units (a) MuCell injection system; (b) a slit mould; (c) a signal monitoring and measuring system; and (d) a gas counter pressure system, as shown in Fig. 2.

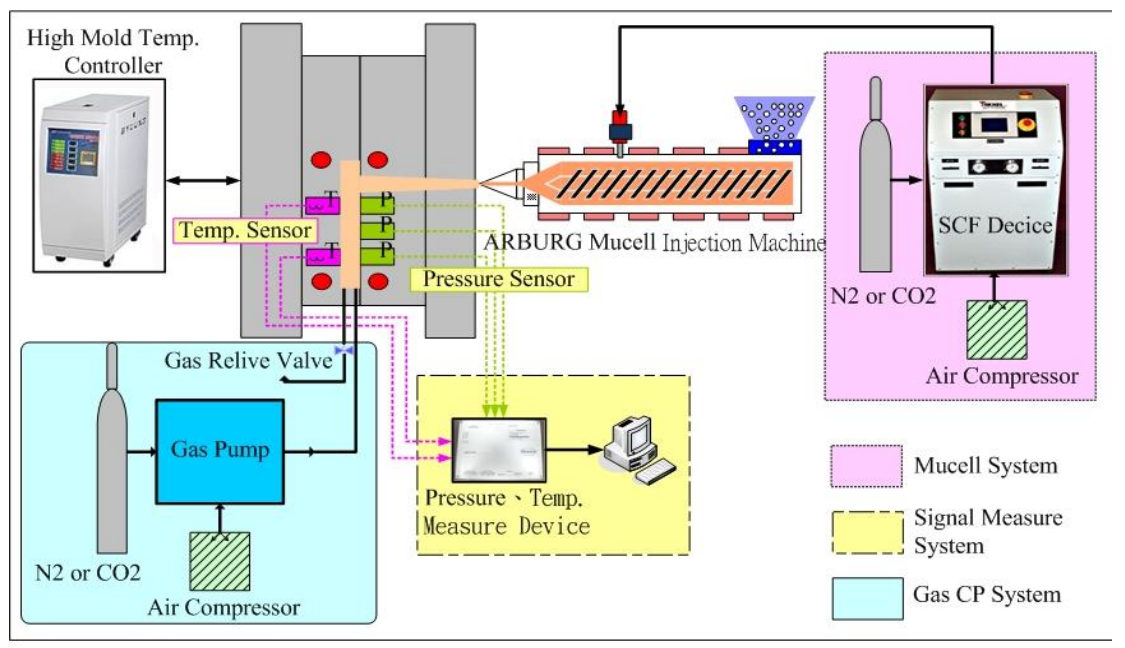

Fig. 2. Schematic of MuCell injection moulding with a gas counter pressure system. [16]

\section{Results and discussion}

The pressure drop was measured by three pressure sensors located along the length of the slit cavity (Fig. 3), while the shear rate was calculated from the velocity of the screw as measured by a displacement transducer. 


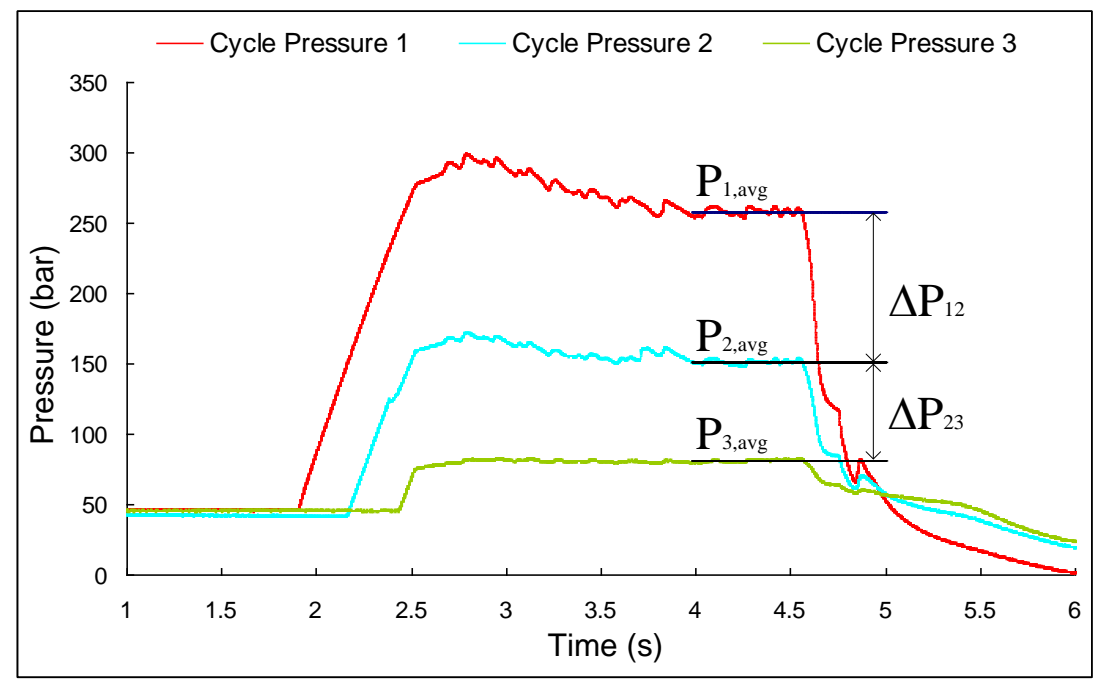

Fig. 3. Determining the pressure drop.

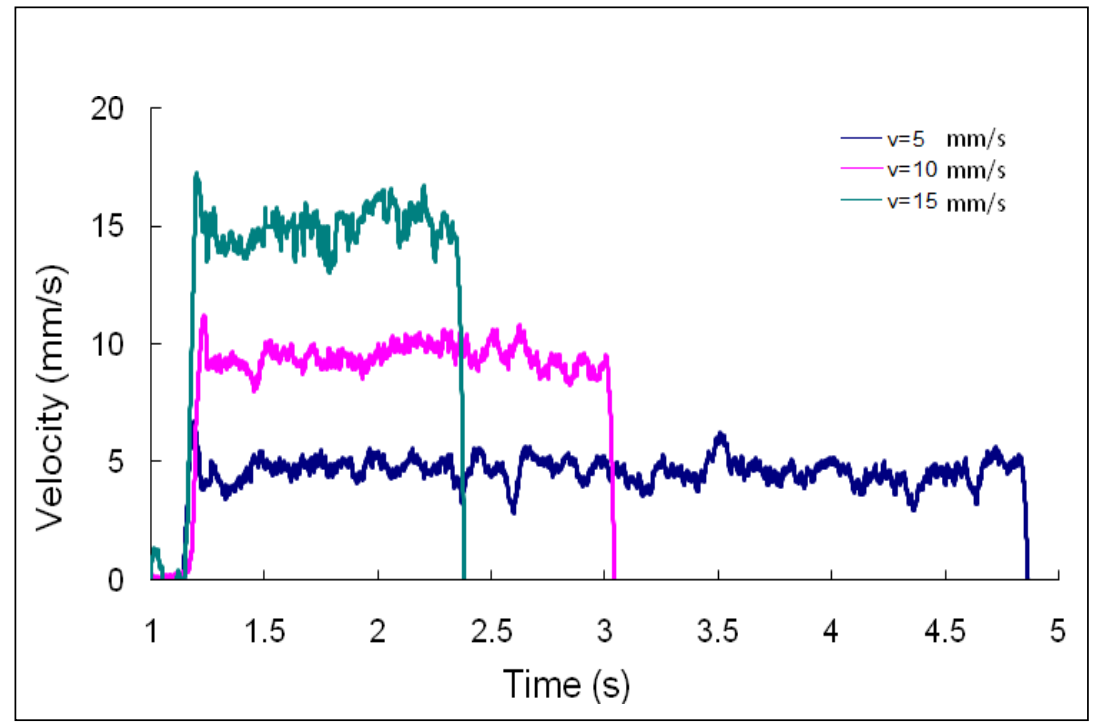

Fig. 4. Stable injection speed curve of MuCell with Gas Counter Process.

The injection speed is shown in Fig. 4. The experimental data of the pressure drop (The pressure transducers $\mathrm{P} 1, \mathrm{P} 2$ and $\mathrm{P} 3$ are different position's pressure of the cavity shown in Fig. 10) were determined at the stable zone (zone IV) in figure.

The modified Cross-WLF model is used to calculate the depressions of $T_{g}$ for PS rein contain dissolved $\mathrm{N}_{2}$. The $\mathrm{T}_{\mathrm{g}}$ at various GCP levels is shown in Fig. 5. We found that $\mathrm{T}_{\mathrm{g}}$ is almost the same when GCP is between 0 150 bar at different injection speeds $(5,10,15 \mathrm{~mm} / \mathrm{s})$. Further, when GCP reaches $300 \mathrm{bar}$, the $T_{g}$ falls from $96{ }^{\circ} \mathrm{C}$ to about $50{ }^{\circ} \mathrm{C}$. It means when $\mathrm{GCP}$ is 300 bar, the $\mathrm{PS} / \mathrm{ScN}_{2}$ maintains a single phase during the injection moulding process.

The viscosity of MuCell injection moulding at various GCP levels is shown in Fig 6 . Different GCP levels can influence the viscosity value. The higher the GCP levels, the more reduction in melt real viscosity. The results shown that the real viscosity clearly decreased when the GCP is 300 bar. 


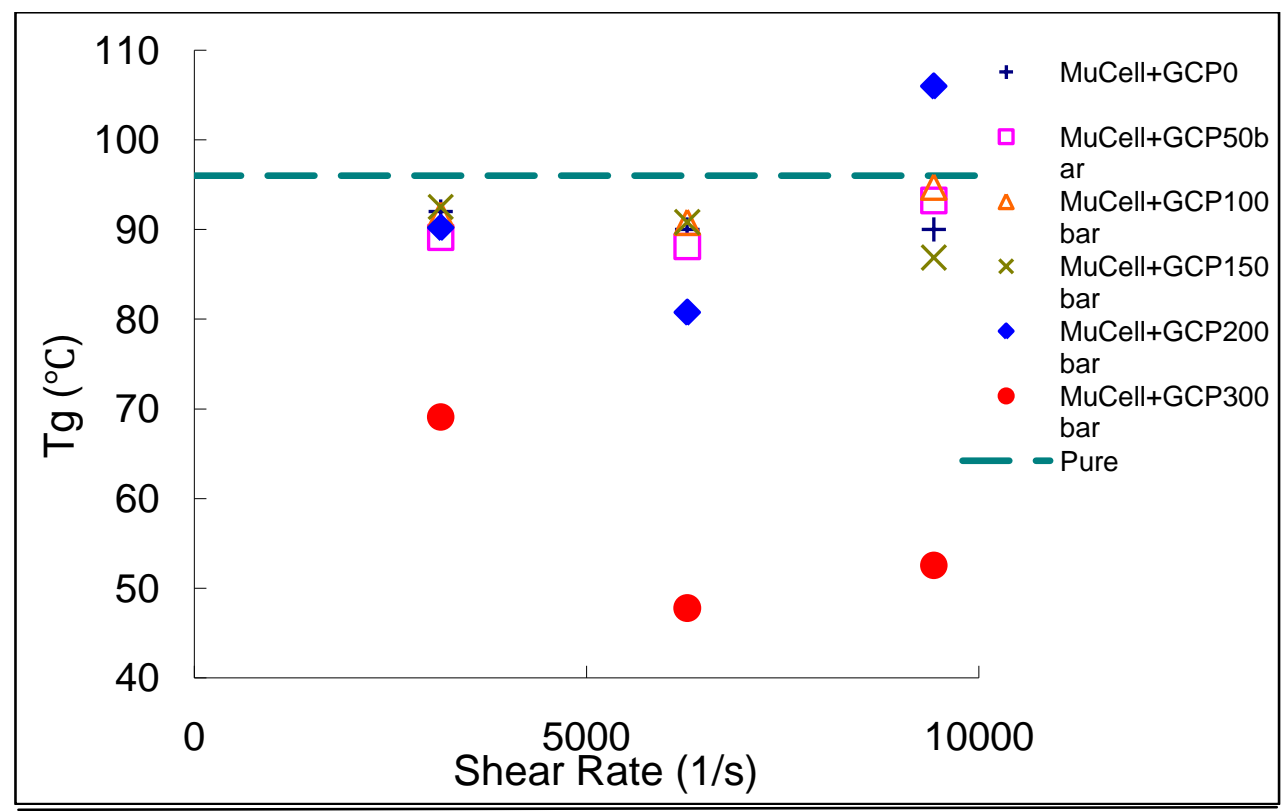

Fig. 5. $T_{g}$ depression of MuCell with GCP.

Fig. 7 shows the viscosity curve at different shear rates when temperature is at 185 ${ }^{\circ} \mathrm{C} \sim 205^{\circ} \mathrm{C}$. When the mould temperature is rising, the viscosity is decreasing at an accelerating rate, as shown in Fig 8. At lower injection speeds, the longer injection time is more effective.

The power law model was used in fitting the experimental data, as follows:

$\eta=m \dot{\gamma}^{n-1}$

The results are shown in Fig 9, in which the shear rate range is between 3000 11000 $\mathrm{s}^{-1}$. When the temperature is rising, the $\mathrm{n}$ of the MuCell at a GCP of 300 bar is increasing in direct proportion. Higher $\mathrm{n}$ means the flow behavior approaches more closely to Newtonian Flow.

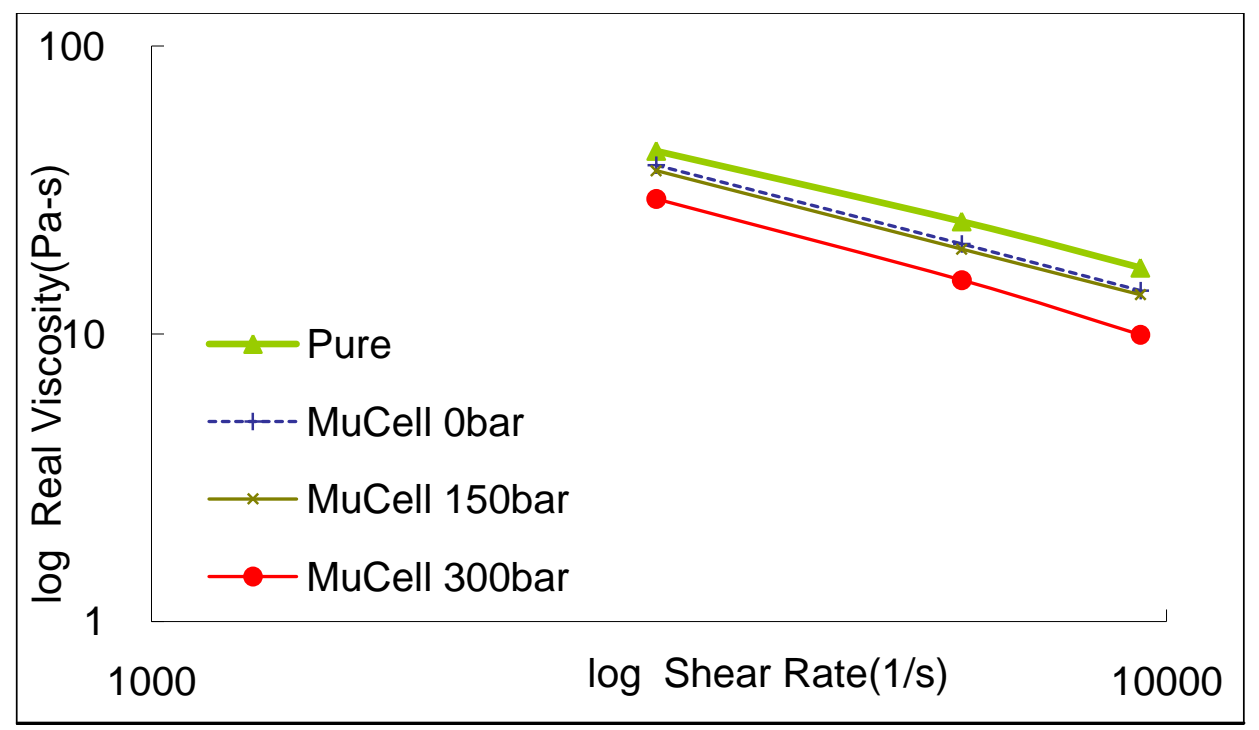

(a) 


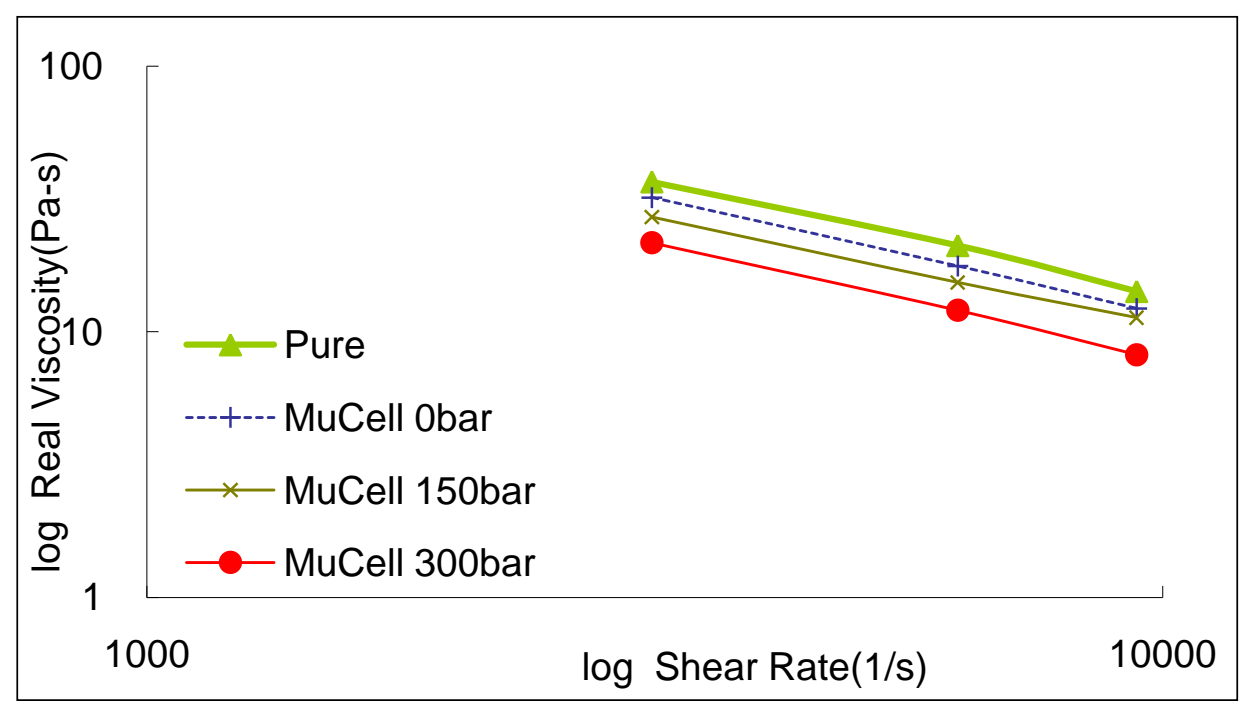

(b)

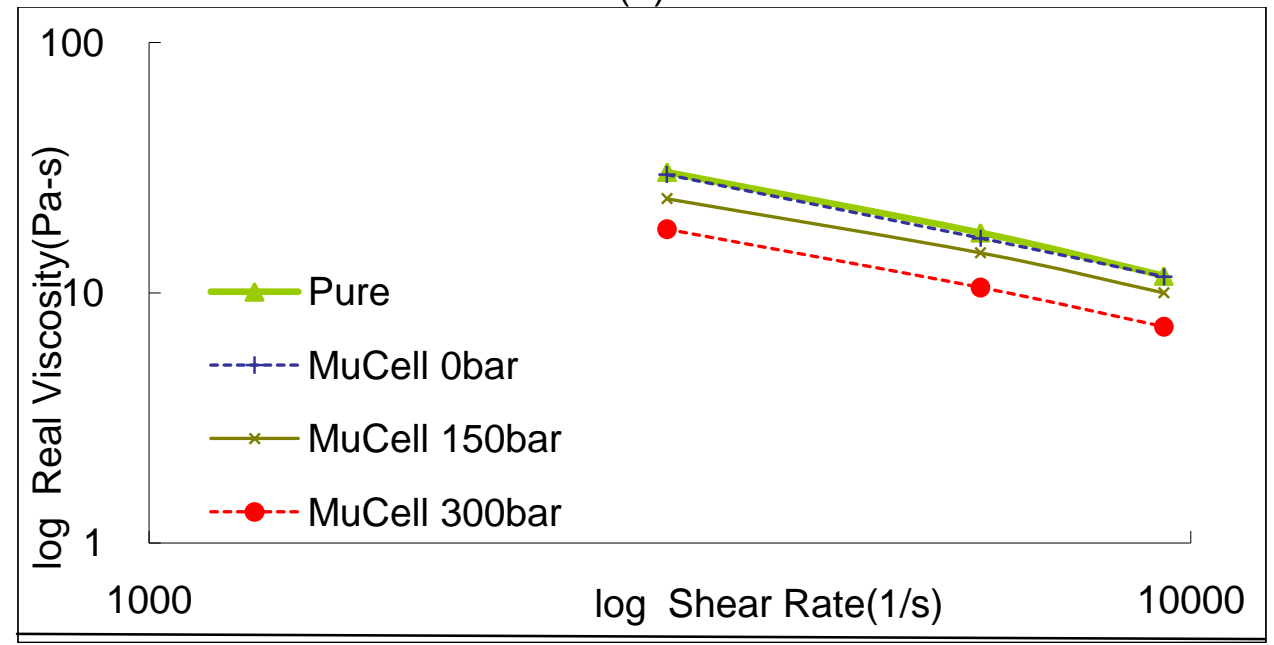

(c)

Fig. 6. Real viscosity curve of different mould temperatures and GCP (a) $185^{\circ} \mathrm{C}$; (b) $195{ }^{\circ} \mathrm{C}$; (c) $205^{\circ} \mathrm{C}$.

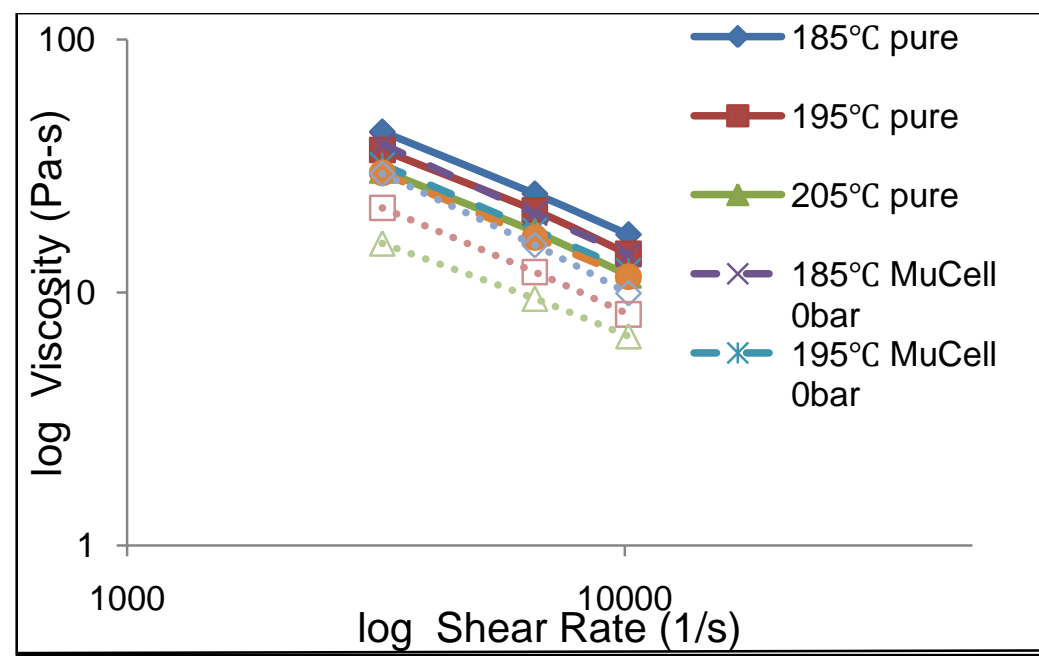

Fig. 7. Real viscosity curve at different shear rates. 


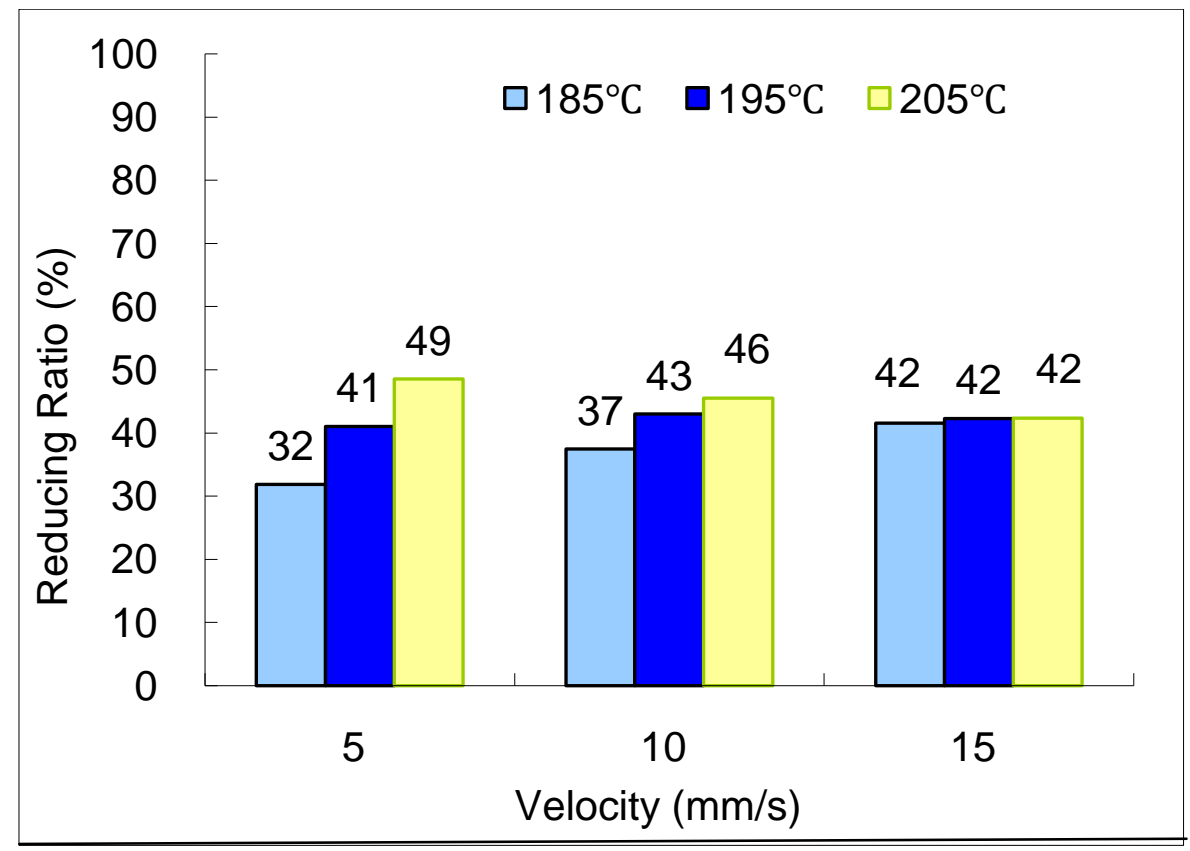

Fig. 8. Viscosity reduction ratios at different mould temperatures and injection shear rates with GCP 300 bar.

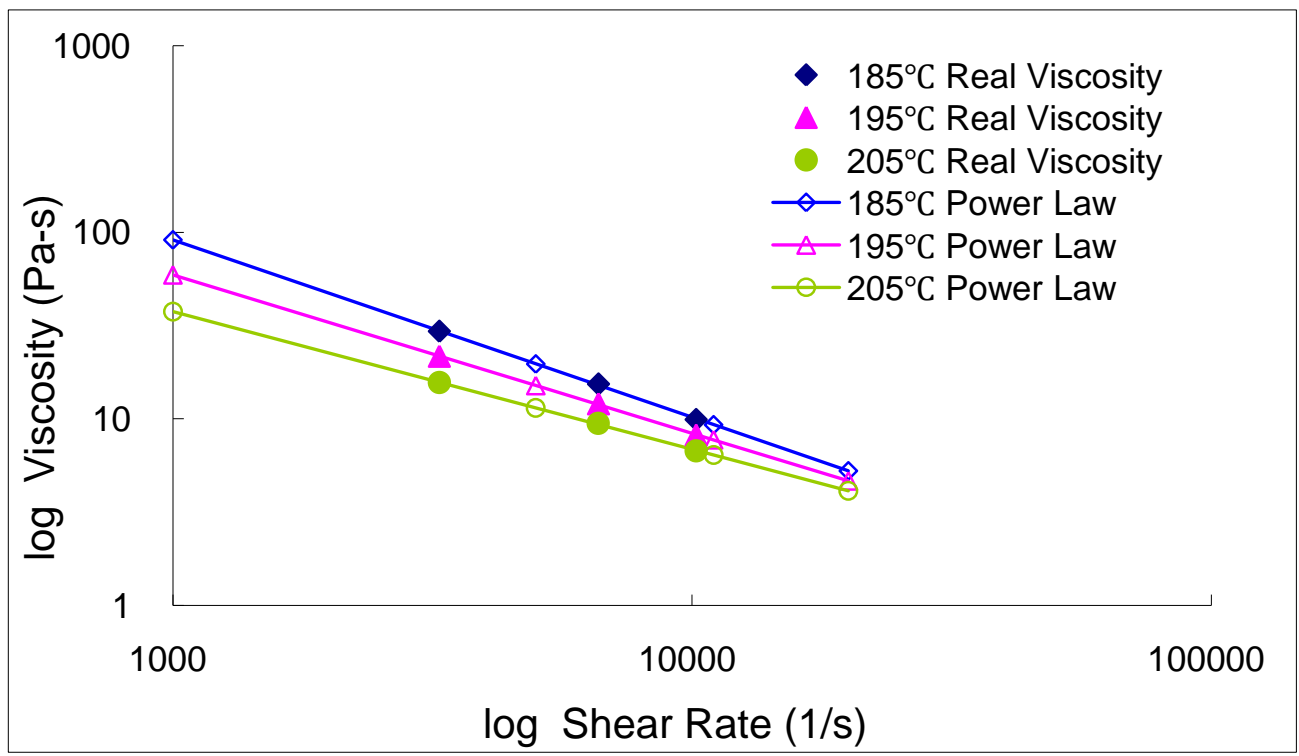

Fig. 9. Experimental data fitting with Power Law model.

\section{Conclusions}

In this study, a Gas Counter Pressure (GCP) system and a slit die rheometer were established to measure a wide range of viscosity for $\mathrm{PS} / \mathrm{ScN}_{2}$. Applying gas into the mould cavity prior to the melt filling provides a counter force against melt front advancement, restricting the foaming process. We observed that during the MuCell injection moulding process, the injection pressure and viscosity clearly decreases. The results of this study are as follows:

1. The injection pressure was decreased by about $15 \sim 45 \%$ when the injection speed was between 5 and $15 \mathrm{~mm} / \mathrm{s}$. 
2. MuCell injection moulding combined with a GCP system can control the cell size uniformly, and reduce the viscosity of the $\mathrm{PS} / \mathrm{ScN}_{2}$ melt by $30 \%$ at GCP pressures of $0 \sim 150$ bar.

3. When the GCP reaches 300 bar, a pressure higher than the bubble pressure of the $\mathrm{PS} / \mathrm{ScN}_{2}, \mathrm{PS} / \mathrm{ScN}_{2}$ melt thus maintains a one-phase mixture and the viscosity of the one-phase $\mathrm{PS} / \mathrm{ScN}_{2}$ melt can be decreased by as much as $50 \%$.

4. At lower GCP (0 150 bar), the decrease in $T_{g}$ was less obvious. But when GCP reached 300 bar, $\mathrm{T}_{\mathrm{g}}$ fell from $96{ }^{\circ} \mathrm{C}$ to $50^{\circ} \mathrm{C}$.

5. The power law model was chosen to fit the experimental data. It shows that within shear rate range is $3000 \sim 11000 \mathrm{~s}^{-1}$, the estimated fitting error is about $2 \%$.

\section{Experimental part}

Polystyrene (POLYREX PG-33, Chemicals) resin was used in this rheology study. The glass-transition temperature $\left(T_{g}\right)$ was confirmed to be $96{ }^{\circ} \mathrm{C}$. Nitrogen $\left(\mathrm{N}_{2}\right)$ was used as the gas source and the dissolved $\mathrm{N}_{2}$ level was set at $0.3 \%$. The volume expansion ratio was $5 \%$ (Table 1 ).

Tab. 1. Experimental parameters.

\begin{tabular}{ccccccccc}
\hline Material & SCF & $\begin{array}{c}\text { Mould } \\
\text { Temp. } \\
\left({ }^{\circ} \mathrm{C}\right)\end{array}$ & $\begin{array}{c}\text { Melt } \\
\text { Temp. } \\
\left({ }^{\circ} \mathrm{C}\right)\end{array}$ & $\begin{array}{c}\text { Injection } \\
\text { Speed } \\
(\mathrm{mm} / \mathrm{s})\end{array}$ & $\begin{array}{c}\text { Back } \\
\text { Pressure } \\
(\text { bar })\end{array}$ & $\begin{array}{c}\text { SCF } \\
\text { inject } \\
\text { time } \\
(\mathrm{s})\end{array}$ & $\begin{array}{c}\text { SCF } \\
\text { flow } \\
\text { ratio } \\
(\text { wt\% })\end{array}$ & $\begin{array}{c}\text { SCF } \\
\text { flow ratio } \\
(\mathrm{Kg} / \mathrm{hour})\end{array}$ \\
\hline \multirow{2}{*}{$\mathrm{PS}$} & \multirow{2}{*}{$\mathrm{N}_{2}$} & 185 & 185 & 5 & 185 & & & \\
& & 195 & 195 & 10 & 187 & 0.9 & 0.4 & 0.21 \\
\hline
\end{tabular}

An Arburg 420C Allrounder 1000-350 machine equipped with a MuCell supercritical fluid system was used for the MuCell rheology experiments. A high temperature mould for measuring MuCell with a Gas Counter Pressure (GCP) system was established to measure the rheology behavior of $\mathrm{PS} / \mathrm{ScN}_{2}$ in the MuCell injection moulding process (Table 2). A stable high mould temperature was provided by a high mould temperature controller and an isolated design in the mould. The system was required to measure the pressure and temperature within the slit cavity above the bubble pressure ensuring that a one-phase mixture was maintained during the injection process. The slit cavity had dimensions of $140 \mathrm{~mm}$ (length) $\times 12 \mathrm{~mm}$ (width) $\times 1 \mathrm{~mm}$ (thickness). The pressure drop and melt temperature across the slit cavity were measured via three pressure sensors (Priamus 6001/B) in the cavity and two temperature sensors (Priamus 4004a) at the core. The date was acquired with monitoring system (Priamus e-Dap). The location of each sensor position is shown in Fig. 10.

Another important design element of this mould is the Gas Counter Pressure (GCP) control system. A high temperature seal was used to prevent gas escaping from the cavity, and a relief control valve device connected to the mould was used to adjust and monitor the real time gas pressure in the mould cavity. 

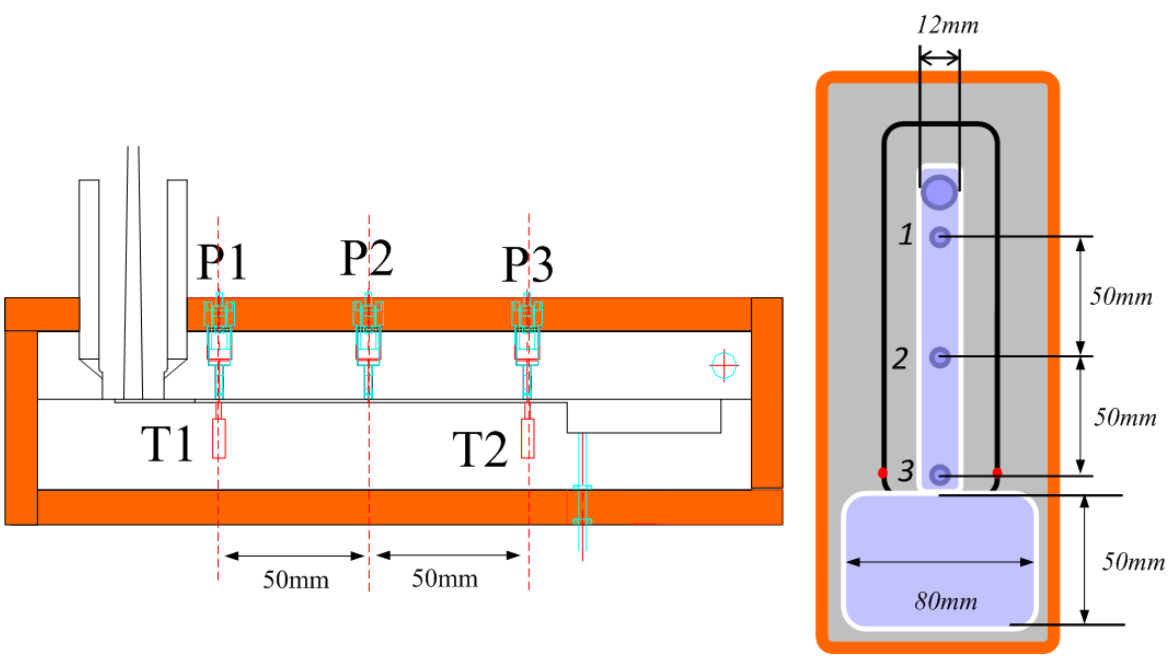

Fig. 10. Slit cavity size and sensor position.

Tab. 2. Gas counter pressure parameters.

\begin{tabular}{lll}
\hline $\begin{array}{l}\text { Shot-off } \\
\text { nozzle delay } \\
\text { time(s) }\end{array}$ & $\begin{array}{l}\text { Gas } \\
\text { inject } \\
\text { time(s) }\end{array}$ & $\begin{array}{l}\text { Gas } \\
\text { pressure } \\
\text { (bar) }\end{array}$ \\
\hline \multirow{3}{*}{1.5} & 5 & 50,100 \\
& 3.5 & 150,200 \\
& 3 & 250,300 \\
\hline
\end{tabular}

\section{Acknowledgements}

Current research is supported by the Center-of-Excellence Program on Membrane Technology from the Ministry of Education; the project of specific research fields and project of outstanding research professor award in the CYCU, Taiwan.

\section{References}

[1] Martini, J. E.; Suh, N. P.; Waldman, F. A. US Patent 4473665, 1984.

[2] Colton, J. S.; Suh, N. P. Polym. Eng. Sci., 1987, 27, no. 7, 500.

[3] Jingyi X. and David P. Trexel report, Trexel Inc., 2001.

[4] Lee, M.; Park, C. B.; Tzoganakis, C. Polym. Eng. Sci. 1999, 39, 99.

[5] Lee, M.; Park, C. B.; Tzoganakis, C. Adv. Polym. Tech. 2000, 19, 300.

[6] Royer, J. R.; Gay, Y. J.; Desimone, J. M.; Khan, S. A. J Polym. Sci. Pol. Phys. 2000, 8, 3168.

[7] Mendelson, R.A. Rheol. J., 1979, 23, 545.

[8] Gerhardt, L. J.; Manke, C. W.; Gulari, E. J Polym. Sci. Pol. Phys. 1997, 35, 3, 523.

[9] Kwag, C.; Manke, C. W.; Gulari, E. J Polym. Sci. Pol. Phys. 1999, 37, 19, 2771.

[10] Lan, H.-Y.; Tseng, H.-C. J. Polym. Res. 2002, 9, 157.

[11] Lee, M.; Park, C.; Tzoganakis, C.; Naguid, H. ANTEC Conference Proceedings 2001, 45, 1241.

[12] Royer, J. R.; DeSimone, J. M.; Khan, S. A. J Polym. Sci. Pol. Phys. 2001, 39, 3055 .

[13] Royer, J. R.; Gay, Y. J.; Desimone, J. M.; Khan, S. A. J Polym. Sci. Pol. Phys. 2000, 38, 3168. 
[14] Bledzki, K.; Kirschling, H.; Steinbichler, G.; Egger, P., ANTEC Conference Proceedings 2004, 3108.

[15] Naruse, H.; Yasuda, K. 2004, JP Patent 2004223879.

[16] Lin Y. W.; Chen S. C. 2008, Doctoral dissertation CYCU. 